\title{
A NEW REFINED JORDAN'S INEQUALITY AND ITS APPLICATION
}

\author{
Ravi P. Agarwal, Young-Ho Kim And S. K. SEN
}

Abstract. New refined lower and upper bound forms of Jordan's inequality are proved. As an application, the lower bound form is shown to improve L. Yang's inequality that plays a pivotal role in the theory of distribution of values of functions. Some numerical results are included.

Mathematics subject classification (2000): 26D15.

Keywords and phrases: distance function, Jordan's inequality, Taylor's formula, Yang's inequality.

\section{REFERENCES}

[1] L. DeBnAth, C.-J. ZhaO, New strengthened Jordan's inequality and its applications, Appl. Math. Lett. 16 (4), (2003) 557-560.

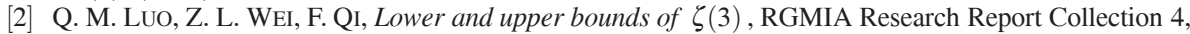
(2001) 565-569.

[3] D. S. Mitrinovic, Integral Analytic Inequalities, Springer-Verlag, 1970.

[4] A. Y. ÖzBAN, A new refined form of Jordan's inequality and its applications, Appl. Math. Lett. 19, (2006) 155-160.

[5] S. H. WU, On generalizations and refinements of Jordan type inequality, RGMIA Research Report Collection 7, (2004) Supplement, Article 2.

[6] L. YANG, Distribution of Values and New Research, Science Press, Beijing, 1982 (in Chinese).

[7] L. ZHU, Sharpening Jordan's inequality and the Yang Le inequality, II, Appl. Math. Lett. 19, (2006) 990-994.

[8] L. ZHU, Sharpening of Jordan's inequality and its applications, Math. Ineq. Appl. Vol. 9, No. 1, (2006) $103-106$.

[9] C.-J. ZHAO, Generalization and strengthen of Yang Le inequality, Mathematics in Practice and Theory 30 (4), (2000) 493-497.

[10] C.-J. ZHAO, On several new inequalities, Chinese Quarterly Journal of Mathematics No. 16 (2), (2001) $42-46$. 